\title{
Antecedents of students' perceptions of online learning through covid-19 pandemic in Jordan
}

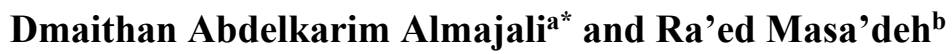

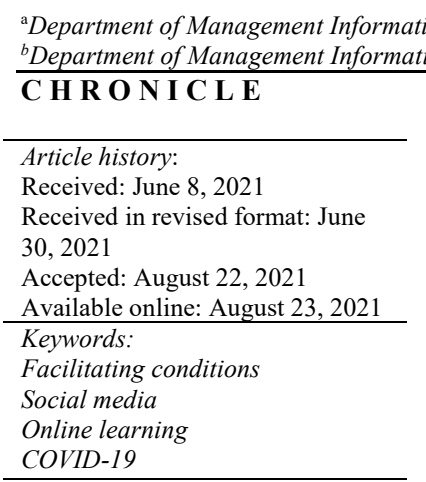

\section{Introduction}

Since the 1990s, technological advancements have resulted in greater usage of web-based technologies in distance education. Many colleges and universities now offer online courses with integrated web-based learning tools (Almajali et al., 2021a; AlFraihat et al., 2020). In today's competitive environment, firms must remodel their information technology infrastructure to successfully advertise services on a global scale (Almajali et al., 2016a). Similarly, the global education system faces tremendous hurdles because of the ongoing COVID-19 pandemic. In 111 countries, according to the World Health Organization (2020), schools were closed, but to ensure that students receive continual education, the traditional brick-and-mortar schools must change into full-time digital schools (Van Lancker \& Parolin, 2020). This change has compelled students to adjust to a fully remote virtual learning, with simultaneous video conferencing serving as the initial venues for knowledge sharing and peer-to-peer interaction. In some countries, like the United States and Canada, only a small number of students have utilized this format before according to Barbour and LaBonte (2017), and transformation to virtual learning may be detrimental to untrained students as it may lead to lower academic achievement (Molnar et al., 2019), a sense of rejection (Song et al., 2004). The current widespread use of online learning could have a long-term impact on the global education system, even after the epidemic; it can potentially speed up and expand the rapid rise of online schools globally (Molnar et al., 2019). Understanding students' learning environments and online learning experiences during the pandemic has thus become critical. In fact, some major issues associated with students' learning experiences throughout the coronavirus pandemic have emerged, including issues associated with the internet connections (Agung et al., 2020; Masa'deh et al., 2013), issues with the IT tools (Bączek et al., 2021; Niemi \& Kousa, 2020), and issues related to the opportunities for effective learning (Yates et al., 2020). Past findings have provided useful information regarding the challenges students face when learning online. However, there was no mention in terms of their future expectations and learning conditions. Furthermore, empirical studies targeting the broad spectrum of secondary school students have been limited. To fill up this vacuum, current research presents the outcomes of a large-scale

* Corresponding author.

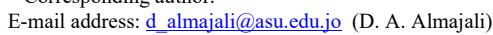


study that investigated the experiences of 350 Jordanian secondary school students who were online learners during the COVID-19 Pandemic. The research findings offer policy suggestions for educational institutions and government agencies regarding the provision of online education to students.

\section{Literature Review}

Students' learning experiences during online learning are dependent on the reliability of the internet access. Indeed, the digitalreadiness gap, as well as the pedagogical approaches used in different countries, could have an impact on students' online learning experiences (Almajali et al, 2016b; Berge, 2005). Digital readiness is defined as a country's availability and acceptance of information technologies and infrastructures (Almajali et al., 2015; Almajali, 2021a). Students from countries with a low level of digital readiness may face additional technology issues. Recent research undertaken throughout the Covid19 pandemic is providing supporting evidence. In Indonesia, more than half of the rural students cited problems including unreliable internet, inadequate internet information, and unsuitable learning gadgets (Al-Dmour et al., 2020; Agung et al., 2020). Furthermore, technical faults with technology gadgets may have an impact on students' online learning experiences. Similarly, students graduating from high school reported experiencing a higher number of technical issues during exam time, necessitating the use of additional technical applications (Niemi \& Kousa, 2020). As a result, it is critical to look at the learning conditions and related issues those students in secondary school face, as the degree of the effects on them is unknown. The feasibility of distance education, according to Song et al. (2004), is dependent on students' experience with online learning, a viewpoint mirrored by Di Slavio (2008), who suggested that users' opinions of online courses will influence distance education's future. According to O'Malley and McGraw (1999), the expansion of online courses has necessitated a study on how this mode of content distribution influences students' perception of their learning. Indeed, student satisfaction in an online learning environment is essential and warrants additional investigation (Roach \& Lemasters, 2006). Relevantly, the current study was created in response to a request for more information on how students evaluate their distance learning experience.

\subsection{Facilitating Conditions}

Facilitating conditions, according to Almajali et al. (2015), are defined as a user's belief that an organizational and Information technology infrastructure exists to facilitate the usage of new information systems. In addition, the extent to which online learning allows for engagement and collaborative learning may have an impact on students' experiences. Feelings of isolation might arise because of online education, affecting students' academic progress (McInnerney \& Roberts, 2004). The incorporation of social contact into online learning pedagogy is thus important, particularly when students' abilities are lacking (Gašević et al., 2015). Unfortunately, the finding reveals that throughout the COVID-19 epidemic, online learning delivery typically lacks interactive and effective experiences (Bączek et al., 2021; Yates et al., 2020). In a survey of high school students conducted by Yates et al. (2020), it was discovered that two-thirds of the students preferred in-class collaboration to online collaboration because in-class engagement provided them with direct support and proximity to their teachers and peers.

\subsection{Ease of Use}

Ease to use refers to users' perceptions of how difficult it is to use technology in an organization. It is an evaluation of how easy it is to use technology without exerting any effort (Almajali et al., 2015). When an alternative approach exists, it is unlikely that a sophisticated system will be adopted. As a result, in voluntary settings, users find these difficult-to-use technologies to be less useful. All school students in all levels may have different opinions on the online activities they want to do, even though this study has provided useful information and highlighted the need for increased online learning participation. In online learning, the rate of assistance is greatly reduced, and students are frequently left to face learning challenges on their own (Barbour, 2013). Self-regulated learning plans are thus important since they facilitate meaningful peer interactions while learning online (Broadbent \& Poon, 2015). In a study conducted by Niemi and Kousa, (2020) involving students graduating from high school, it was discovered that students frequently reported significant workload and weariness when learning online. These concerns may induce anxiety and lower students' willingness to learn, thus impacting their mental wellbeing and educational achievement (Niemi \& Kousa, 2020; Yates et al., 2020). It is therefore important to look at the discrepancies between online learning objectives and the ease-of-use issue with secondary school students in order to better meet their demands.

\subsection{Social Media}

Businesses may utilize social media to build positive relationships with their customers and enhance user engagement (Park \& Kim, 2014). Meanwhile, the topic of social interactions has been gaining increased interest, particularly when it comes to user engagement (Scholtz, 2014). Relevantly, users of social networking sites can create their own virtual communities (Mueller et al., 2011; Almajali, 2021d). Social media implementation out-of-school contexts and early education have been studied in educational research, including primary and secondary school education (Greenhow \& Askari, 2017; Greenhow et al., 2020). Twitter (Gao et al., 2012) and Facebook are two of the most used and studied social media platforms in the educational sector (Greenhow et al., 2020), and some of studies have found that using social media in education has good consequences, such as new chances for connection, collaboration, and content exchange (Li \& Greenhow, 2015; Almajali, 2021c). The pandemic of COVID-19 has radically constrained distance learning, and the use of social media to assist active learning is one method to get around these constraints. Social media can assist distance education students in reducing some of the distance (Almajali, 2021b; Smith \& Taveras, 2005). 


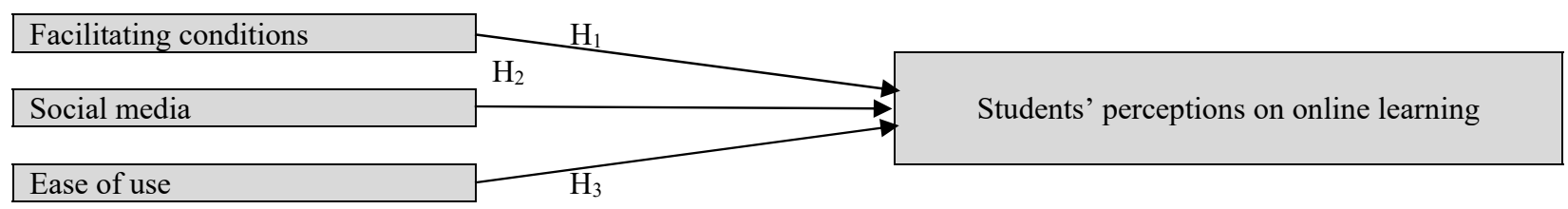

Fig. 1. Research model

The following are the formalized hypotheses:

Hypothesis $1\left(\mathbf{H}_{\mathbf{1}}\right)$. There is a significant effect of facilitating conditions on Students' perceptions of online learning.

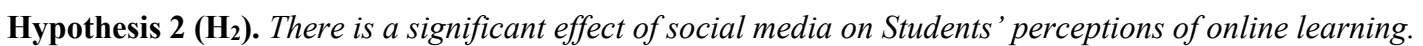

Hypothesis $3\left(\mathbf{H}_{3}\right)$. There is a significant effect of Ease of use on Students' perceptions of online learning.

\section{Research Methods}

\subsection{Pilot Test and Data Collection}

A pilot test was conducted with two MIS academic experts. They were chosen by the researcher based on their prior experience in online education. The sample frame was determined by the ministry of education (https://www.moe.gov.jo). When there are stratum populations available and able to offer the information needed, stratified random sampling may be the optimal method of sampling (Sekaran, 2003). All Jordanian secondary school students who learned online were included in the study. An initial analysis of the response conducted is shown in Table 1 below. The total number of secondary school students in the three regions is 170,000. A total of 400 questionnaires were issued, and 350 people responded to the survey, resulting in an $87 \%$ response rate.

Table 1

Summary of Survey Field Work

\begin{tabular}{ccc}
\hline Region & Number ofsecondary school Students & Percentage \\
\hline North & 110 & $31.4 \%$ \\
Center & 180 & $51.4 \%$ \\
South & 60 & $17.1 \%$ \\
\hline
\end{tabular}

\subsection{Construct Measurement}

To meet the objective of the study, an electronic survey was utilized to gather data from a sample of relevant Students. All online questionnaire measures were adapted from previous research. To evaluate the use of social media, 4 items adapted from Hajli and Lin (2015) were used. For the construct of facilitating conditions, a 6 items scale was established (Almajali et al., 2015). Based on (Almajali et al., 2015), a 4-item scale was constructed to assess Ease to use. For evaluating the Students' Perceptions of Online Learning, 6 items were adapted from Smart and Cappel (2006). The measurement items were modified to fit the research domain and were scored on a 7-point Likert scale ranging from 1 (strongly disagree) to 7 (strongly agree).

\subsection{Data Analysis and Results}

Several statistical tests were conducted to see if the antecedents listed above had an impact on students' perceptions of online learning in Jordan. Indeed, using SEM techniques, the relationship between three students' perceptions of online learning antecedents was empirically evaluated. In evaluating our first defined model, Table 2 shows many forms of goodness of fit indices. We also looked at the standardized regression weights of the research indicators and found that some of them had a low loading towards the latent variables including: $\mathrm{FC} 2=0.311, \mathrm{SM} 1=0.241, \mathrm{SM} 2=0.211, \mathrm{EU} 1=0.402, \mathrm{SP} 3=0.422$. Furthermore, none of these items met the recommended minimum factor loading value of 0.50 (Newkirk \& Lederer, 2006), and the first fit indices for the sample data were moderate, and thus, they were all deleted and omitted from further analysis. As a result, the measurement model was adjusted to better match the data (as shown in Table 2 below). The IFI $=0.84$, TLI $=0.86$, and CFI $=0.89$ suggested a better fit to the data after the low factor loading items were removed, while the final model's $\chi^{2} / \mathrm{df}$ and RMSEA remained unchanged (See Table 2 below).

Table 2

Measurement Model Fit Indices

\begin{tabular}{ccccccccc}
\hline Model & $\boldsymbol{\chi}^{\mathbf{2}}$ & $\mathbf{D f}$ & $\mathbf{P}$ & $\mathbf{x}^{\mathbf{2}} / \mathbf{d f}$ & IFI & TLI & CFI & RMSEA \\
\hline Initial Estimation & 1423.133 & 644 & 0.00 & 2.20 & 0.73 & 0.77 & 0.72 & 0.101 \\
Final model & 772.111 & 455 & 0.00 & 1.69 & 0.84 & 0.86 & 0.89 & 0.08 \\
\hline
\end{tabular}


After modifying the final measurement model, the four constructs were evaluated for unidimensionality, reliability, and validity.

\subsection{Unidimensionality}

According to Byrne (2001), evaluating unidimensionality entails determining the standardized factor loadings. The result in this study provides strong evidence for the measurement model's four components being unidimensional. All of the parameter estimates were within 0.50 of the recommended minimum values (Newkirk \& Lederer, 2006).

\subsection{Reliability}

To determine the degree to which the research scales represent the research's latent components, the reliability of the research scales must be studied. Cronbach's alpha and composite reliability are two tests that are commonly used to assess construct reliability (Hair et al., 1998). The results show that all Cronbach's alpha values for the four constructs is above the acceptable value of 0.60 , indicating that the instrument is reliable, according to (Bagozzi \& Yi, 1988). Furthermore, composite reliability values ranged from 0.80 to 0.93 , all of which were higher than the recommended value of 0.60 (Bagozzi \& Yi, 1988). All of the research constructs in this study are declared reliable as a result of the two tests mentioned above.

\subsection{Validity: Convergent and Discriminant}

While the convergent validity test is necessary in the Measurement model to verify if the indicators on a scale load together on a single construct, the discriminant validity test ensures that the items supposed to measure separate constructs are indeed evaluating different constructs. As demonstrated in the results, all items were significant, with loadings more than 0.50 on their underlying constructs. A variety of tests were used to look into discriminant validity. First, Discriminant validity can be investigated in the measurement model by looking at the latent constructs shared average variance (AVE). It can also be investigated by looking for any extremely large correlations, which would signal that the model has a discriminant validity problem. Furthermore, discriminant validity arises when each construct's AVE exceeds the square correlation between that construct and other constructs (Fornell \& Larcker, 1981). As a consequence, all of the constructs explained 50\% or more of the variation, with AVE values ranging from 0.84 to 0.95 , meeting the criterion that AVE values for each construct be at least 0.50 (Fornell \& Larcker, 1981). However, discriminant validity was established because the AVE values for each set of constructs were greater than the squared correlations. As a result, the metrics effectively distinguish between the constructs.

\subsection{Hypotheses Testing and Discussion}

The findings of the empirical investigation, as presented in this study, provided intriguing results for discussion, extending earlier research in the areas of students' perceptions of online learning. Three propositions relating to the study's goals were established and tested, as shown in Table 3. Three propositions were found to be true, and the results show that Facilitating conditions have a substantial impact on students' perceptions on online learning $(p=0.032)$. As a result, H1 is supported. H2 is supported by the fact that students' perceptions of online learning are significantly improved by social media $(p=0.013)$. Ease of use has a significant impact on students' perceptions of Online Learning ( $p=* * *)$, so, H3 is supported. The impact of the pandemic on Jordanian secondary school students' e-learning experience and perception was investigated in this study. The students that took part in the survey came from all regions of Jordan. Prior to the pandemic, most students had never taken an online class. This implies a lack of utilization of technology in the teaching and learning process. Meanwhile, such utilization is the responsibility of the schools. Schools should put more money into the technology that helps them teach and learn. According to our findings, many students experienced significant e-learning barriers, and a large percentage of students have been unable to attend online classes. Students from rural and isolated places, for example, have been hampered by bad economic situations and learning environments, as well as poor Internet connectivity. The study found that facilitating conditions have a positive impact on students' perceptions of online learning. Additionally, students were facing various difficulties and challenges during the Covid-19 pandemic, including anxiety, lack of a device to attend online classes, lack of a separate room to study at home, and Internet connectivity issues. Furthermore, online learning delivery for students should emphasize more on the students' opportunities to speak with one another and participate in collaborative learning. Students can achieve this goal by being assigned or encouraged to partake in online group activities (Bickle \& Rucker, 2018). Appositely, the findings of this study suggest that social media has a significant impact on students' perceptions of online learning. Additionally, a growing body of research demonstrates that a user's experience with technology influences their attitudes toward technology in general (Gefen et al., 2003). The more experience users have with technology, the more satisfied they are with their ability to learn new technologies (Simmers \& Anandarajan, 2001). The findings of our study reveal that students who experience ease in using technology in e-learning demonstrated positive perceptions towards online learning.

Table 3

Summary of the Theoretical Model Proposed Results

\begin{tabular}{|c|c|c|c|c|}
\hline Study Proposed Paths & $\begin{array}{c}\text { Coefficients Value } \\
\text { (std. estim) }\end{array}$ & $\begin{array}{l}\text { t-Value } \\
\text { C.R }\end{array}$ & $p$-Value & $\begin{array}{l}\text { Empirical } \\
\text { Evidence }\end{array}$ \\
\hline P1:Facilitating conditions $\rightarrow$ Students' Perceptions of Online Learning & 0.115 & 2.210 & 0.032 & Supported \\
\hline P2:Social media $\rightarrow$ Students' Perceptions of Online Learning & 0.147 & 2.262 & 0.013 & Supported \\
\hline P3:Ease to use $\rightarrow$ Students' Perceptions of Online Learning & 0.301 & 7.122 & $* * *$ & Supported \\
\hline
\end{tabular}

$* * * p \leq 0.05$. 


\section{Limitations and Conclusions}

The purpose of this study was to gain a better understanding of students' perceptions of online learning. The study's main purpose was to address a vacuum in previous studies on students' experiences on online learning after being forced to relocate due to the extraordinary pandemic. The analysis was concluded by looking into the major issues that arose during the lockdown. Our findings on the lack of preparedness of ICT technologies employed in Jordanian schools have a second key limitation: Jordanian schools should make greater use of ICT technology and update their teaching and learning approaches to modernize their educational system. Finally, we should mention that a problem with the scales employed in this study may have influenced the results; seven-point scales were utilized for most of the survey's satisfaction or strongly disagree/strongly agree with opinion items. Here, "I don't know/no opinion" was the scale's midpoint. Considering that "don't know" does not always imply an opinion between "slightly agree" and "slightly disagree," it would have been more suitable to label the midpoint "neutral" or "neither agree/disagree" to represent the viewpoints of respondents more accurately. Also, considering that survey participants who marked "don't know/no opinion" may not have appropriately responded between slightly satisfied and slightly dissatisfied, the term used may have resulted in some involuntary bias of the findings, either negatively or positively.

\section{References}

Agung, A.S.N., Surtikanti, M.W., \& Quinones, C.A. (2020). Students' perception of online learning during COVID-19 pandemic: a case study on the English students of STKIP Pamane Talino. SOSHUM: Jurnal Sosial Dan Humaniora, 10(2), 225-235. https://doi.org/10.31940/soshum.v10i2.1316.

Al-Dmour, H., Masa'deh, R., Salman, A., Abuhashesh, M., \& Al-Dmour, R. (2020). Influence of social media platforms on public health protection against the COVID-19 pandemic via the mediating effects of public health awareness and behavioral changes: Integrated model. Journal of Medical Internet Research, 22(8). doi:10.2196/19996

Al-Fraihat, D., Joy, M., Masa'deh, R., \& Sinclair, J. (2020). Evaluating E-learning systems success: an empirical study. Computers in Human Behavior, 102, 67-86. doi:10.1016/j.chb.2019.08.004

Almajali, D. (2021a). Antecedents of ecommerce on actual use of international trade center: literature review. Academy of Strategic Management Journal, 20(2), 1-10.

Almajali, D. (2021b). Diagnosing the effect of green supply chain management on firm performance: an experiment study among Jordan industrial estates companies. Uncertain Supply Chain Management, 9(4), 1-8.

Almajali, D., Hammouri, Q., \& Barakat, S. (2021c). E-learning through COVID-19 crisis in developing countries. International Journal of Pharmaceutical Research, 13(1), 5543-5553.

Almajali, D., Hammouri, Q., Majali., T., AL-Gasawneh., J., Dahalin, Z. (2021d). Antecedents of consumers' adoption of electronic commerce in developing countries. International Journal of Data and Network Science, 5(4), 1-10.

Almajali, D., Maqableh, M., \& Masa'deh, R. (2015). Assessing the digital divide status of the Jordanian telecentre. International Journal of Communications, Network and System Sciences, 8, 428-439. 10.4236/ijcns.2015.811039.

Almajali, D., Masa'deh, R., \& Al-Lozi, M. (2016a). Determinants of the actual use of e-learning systems: an empirical study on Zarqa university in Jordan. Journal of Social Sciences (COES\&RJJSS), 5(2), 172-200.

Almajali, D., Masa'deh, R., \& Tarhini, A. (2016b). Antecedents of ERP systems implementation success: a study on Jordanian healthcare sector. Journal of Enterprise Information Management, 29(4), 549-565.

Bączek, M., Zagańczyk-Bączek, M., Szpringer, M., Jaroszyński, A., \& Wożakowska-Kapłon, B. (2021). Students’ perception of online learning during the COVID-19 pandemic: a survey study of Polish medical students. Medicine, $100(7)$, e24821.

Bagozzi, R.P., \& Yi, Y. (1988). On the evaluation of structural equation models. Journal of the Academy of Marketing Science, 16(1), 74-94.

Barbour, M.K. (2013). The landscape of k-12 online learning: examining what is known. Handbook of Distance Education, 3, 574-593.

Barbour, M.K., \& LaBonte, R. (2017). State of the Nation:secondary school e-Learning in Canada, 2017. Available online: k12so tn.ca/wp-content/uploads/2018/02/StateNation17.pdf (accessed on 10/4/2021).

Berge, Z.L. (2005). Virtual Schools: Planning for Success. Columbia University, Teachers College Press: Columbia, COL, USA.

Bickle, M.C., \& Rucker, R. (2018). Student-to-student interaction: humanizing the online classroom using technology and group assignments. Quarterly Review of Distance Education, 19(1), 1-56.

Broadbent, J., \& Poon, W.L. (2015). Self-regulated learning strategies \& academic achievement in online higher education learning environments: a systematic review. The Internet and Higher Education, 27, 1-13.

Byrne, B. (2001). Structural Equation Modeling with Amos: Basic Concept, Applications, and Programming. Mahwah, NJ: Erlbaum, USA.

Di Slavio, P. (2008). Aligning Faculty Incentives with Shifting Modes of Delivery. Academic Leader Magna Online Seminar, https://www.magnapubs.com/product/subscription/academic-leader/ 2008, accessed on 1/4/2021.

Fornell, C., \& Larcker, D.F. (1981). Evaluating structural equation models with unobservable variables and measurement error. Journal of Marketing Research, 18(1), 39-50.

Gao, F., Luo, T., \& Zhang, K. (2012). Tweeting for learning: a critical analysis of research on microblogging in education published in 2008-2011. British Journal of Educational Technology, 43(5), 783-801. 
Gašević, D., Adesope, O., Joksimović, S., \& Kovanović, V. (2015). Externally-facilitated regulation scaffolding and role assignment to develop cognitive presence in asynchronous online discussions. The Internet and Higher Education, 24, 5365. https://doi.org/10.1016/j.iheduc.2014.09.006

Gefen, D., Karahanna, E., \& Straub, D.W. (2003). Inexperience and experience with online stores: the importance of TAM and trust. IEEE Transactions on Engineering Management, 50(3), 307-321.

Greenhow, C., \& Askari, E. (2017). Learning and teaching with social network sites: a decade of research in K-12 related education. Education and Information Technologies, 22(2), 623-645.

Greenhow, C., Galvin, S., Brandon, D., \& Askari, E. (2020). A decade of research on K-12 teaching and teacher learning with social media: insights on the state-of-the-field. Teachers College Record, 122(6).

Hajli, N., \& Lin, X. (2015). Consumer Adoption of Social Commerce, pp. 279-287, Springer International Publishing: Cham,Switzerland.

Hair, J., Black, W., Babin, B., Anderson, R., \& Tatham, R. (1998). Multivariate Data Analysis. Prentice hall Upper Saddle River, N.J.

Li, J., \& Greenhow, C. (2015). Scholars and social media: tweeting in the conference backchannel for professional learning. Educational Media International, 52(1), 1-14.

McInnerney, J.M., \& Roberts, T.S. (2004). Online learning: social interaction and the creation of a sense of community. Journal of Educational Technology \& Society, 7(3), 73-81.

Masa'deh, M.T.R., Shannak, R.O., \& Mohammad Maqableh, M. (2013). A structural equation modeling approach for determining antecedents and outcomes of students' attitude toward mobile commerce adoption. Life Science Journal, 10(4), 2321-2333.

Molnar, A., Miron, G., Elgeberi, N., Barbour, M.K., Huerta, L., Shafer, S.R., \& Rice, J.K. (2019). Virtual schools in the US 2019. National Education Policy Center, University of Arizona.

Mueller, J., Hutter, K., Fueller, J., \& Matzler, K. (2011). Virtual worlds as knowledge management platform-a practiceperspective. Information Systems Journal, 21(6), 479-501.

Newkirk, H.E., \& Lederer, A.L. (2006). The effectiveness of strategic information systems planning under environmental uncertainty. Information \& Management, 43, 481-501.

Niemi, H.M., \& Kousa, P. (2020). A case study of students' and teachers' perceptions in a finnish high school during the COVID pandemic. International Journal of Technology in Education and Science, 4(4), 352-369. https://doi.org/10.46328/ijtes.v4i4.167

O’Malley, J., \& McGraw, H. (1999). Students perceptions of distance learning, online learning and the traditional classroom. Online J. Distance Learn. Adm. 2. Available online: https://www.westga.edu/ distance/omalley24.html (accessed on 15/4/2021).

Park, H., \& Kim, Y.K. (2014). The role of social network websites in the consumer-brand relationship. Journal of Retailing and Consumer Services, 21, 460-467, doi: 10.1016/j. jretconser.2014.03.011.

Roach, V., \& Lemasters, L. (2006). Satisfaction with online learning: a comparative descriptive study. Journal of Interactive Online Learning, 5(1), 317-332.

Scholtz, R. (2014). Social Media Tools Influencing Customer Purchasing Behavior in the Retail Environment. Master Thesis Dissertation, Nelson Mandela Metropolitan University, Port Elizabeth, South Africa.

Sekaran,U. (2003). Research Methods for Business. New York: Hermitage PublishingServices.

Simmers, C.A. \& Anandarajan, M. (2001). User satisfac-tion in the internet-anchored workplace: an exploratory study. Journal of Information Technology Theory and Application, 3(5), 39-53.

Smart, K.L., \& Cappel, J.J. (2006). Students' perceptions of online learning: a comparative study. Journal of Information Technology Education, 5(3), 201-219.

Smith, G.G., \& Taveras, M. (2005). The missing instructor: does e-learning promote absenteeism?. eLearn Magazine, 2005(1), available at: www.elearnmag.org/subpage.cfm?section= tutorials\&article=18-1 (accessed on 8/4/2021).

Song, L., Singleton, E.S., Hill, J.R., \& Koh, M.H. (2004). Improving online learning: student perceptions of useful and challenging characteristics. The Internet and Higher Education, 7(1), 59-70.

Van Lancker, W., \& Parolin, Z. (2020). Covid-19, school closures, and child poverty: a social crisis in the making. Lancet Public Health, 5(5), e243-e244. https://doi.org/10.1016/S2468-2667(20)30084-0

World Health Organization (2020). Coronavirus Disease 2019 (COVID-19): Situation Report-164 (Situation Report No. 164). Available online: www.who.int/docs/default-source/coronaviruse/situation-reports/20200 702-covid-19-sitrep164.pdf? sfvrsn $\$=\$ a c 074 f 58 \$ \$ 2$ (accessed on 3/4/2021).

Yates, A., Starkey, L., Egerton, B., \& Flueggen, F. (2020). High school students' experience of online learning during Covid19: the influence of technology and pedagogy. Technology, Pedagogy and Education, 9, 1-15. https://doi.org/10.1080/1475939X.2020.1854337.

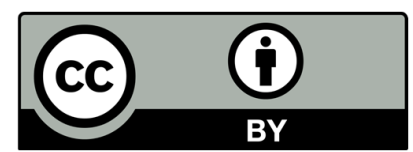

(C) 2021 by the authors; licensee Growing Science, Canada. This is an open access article distributed under the terms and conditions of the Creative Commons Attribution (CC-BY) license (http://creativecommons.org/licenses/by/4.0/). 